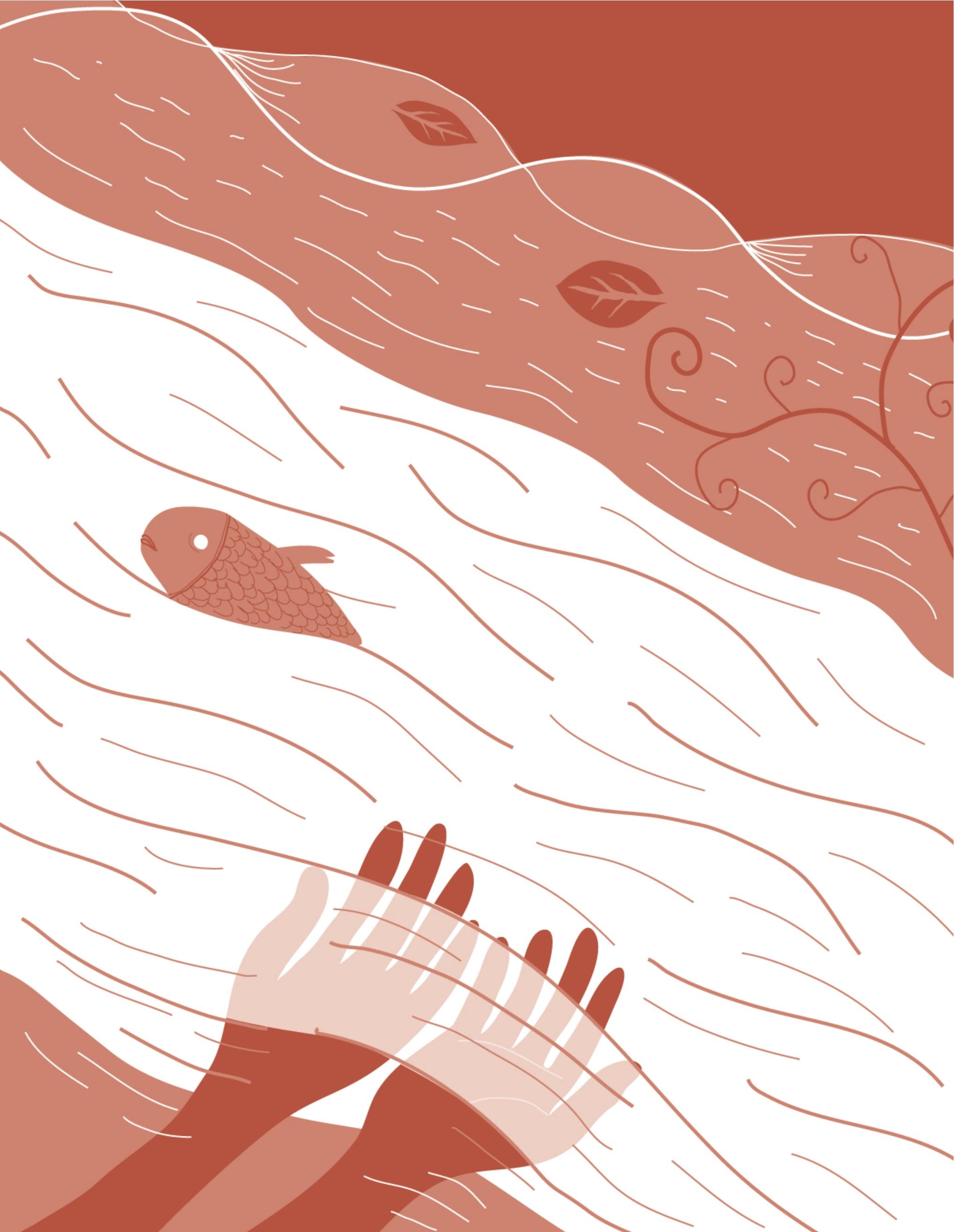




\section{Informação, relações de poder e Comunicação nas organizações: uma reflexão sobre o campo}

Denise da Costa Oliveira Siqueira

- Doutora em Ciências da Comunicação pela Escola de Comunicações e Artes da Universidade de São Paulo (ECA-USP)

- Mestre em Ciência da Informação pela Escola de Comunicação da Universidade Federal do Rio de Janeiro (ECO-UFRJ)/Ibict-CNPq

- Especialista em Sociologia Urbana pelo Instituto de Filosofia e Ciências Humanas da Universidade do Estado do Rio de Janeiro (IFCH-Uerj)

- Graduada em Comunicação Social com habilitação em Jornalismo e Relações Públicas pela Faculdade de Comunicação Social (FCS) da Uerj

- Professora adjunta, pesquisadora e orientadora da FCS-Uerj na graduação, especialização em Jornalismo Cultural e mestrado em Comunicação

- Editora da revista Logos - Comunicação e Universidade do Programa de Pós-Graduação em Comunicação (PPGC) da Uerj

- Membro do comitê editorial da revista eletrônica Contemporânea do PPGC-Uerj

- Autora de Corpo, comunicação e cultura: a dança contemporânea em cena (Campinas: Autores Associados, 2006) e de A ciência na televisão: mito, ritual e espetáculo (São Paulo: Annablume, 1999)

- denisedacosta@ig.com.br

-dcos@uerj.br 
Resumo

Elemento fundamental nas sociedades e nas organizações contemporâneas, a informação pode articular, promover ou submeter-se a relações de poder. Partindo desta premissa, este artigo tem como objetivo apontar aspectos que possibilitem uma discussão acerca da informação e das relações de poder no âmbito da Comunicação Organizacional e das atividades de Relações Públicas.

PALAVRAS-CHAVE: INFORMAÇÃO • RELAÇÕES DE PODER • COMUNICAÇÃO NAS ORGANIZAÇÕES

\section{Abstract}

As an essential element in contemporary societies and organizations, information can articulate, promote or be subject to power relations. On such premise, this article has the aim of pointing out aspects that make it possible to discuss power relations in the sphere of Organizational Communication and of Public Relations activities.

KEYWORDS: INFORMATION • POWER RELATIONS • COMMUNICATION IN ORGANIZATIONS

\section{Resumen}

Elemento fundamental en las sociedades contemporáneas, la información puede articular, promover o someterse a relaciones de poder. Partiendo de esa premisa, el artículo tiene como objetivo proponer cuestiones que posibiliten la discusión sobre la información y las relaciones de poder en él ámbito de la Comunicación Organizacional y de las actividades de Relaciones Públicas.

PALABRAS CLAVE: INFORMACIÓN - RELACIONES DE PODER - COMUNICACIÓN EN LAS ORGANIZACIONES 
E lemento fundamental na vida urbana contemporânea, a informação se multiplica em quantidade, mas não parece seguir o mesmo percurso em termos qualitativos. O excesso de informação produzido por cientistas, pesquisadores, técnicos especializados em pesquisas de mercado e de opinião, jornalistas e publicitários - potencializado pelas novas tecnologias de comunicação, veiculado por meios de comunicação de massa e pelas redes conectadas de computadores - não fez com que as populações de países como os latino-americanos se tornassem mais esclarecidas em todos os seus níveis. Assim como os demais produtos em uma economia capitalista neoliberal, informação tornou-se mercadoria e, como tal, concentrada nos domínios de determinados grupos sociais. A produção exagerada não provocou, então, sua socialização ou sua democratização, mas gerou, sim, o que autores como Baudrillard (1996) chamaram de "superinformação inútil", que poderia pretender esclarecer, mas não esclarece, pois a velocidade de rotação da informação parece aumentar "o peso das massas em vez de sua tomada de consciência” (BAUDRILLARD, 1996, p. 80).

Apesar de não ter sido utilizada em prol da solução de problemas sociais seculares, informação mostra-se ainda elemento de importância crescente nas sociedades atuais - por promover processos de desenvolvimento econômico, mas também por deter o potencial de, aliada a programas específicos, ajudar a formar cidadãos, a diminuir diferenças econômicas e sociais. Por isso, e por circular nos espaços artísticos, científicos e acadêmicos, no âmbito profissional da comunicação, no universo político e econômico e no campo das organizações, informação se aproxima do campo do poder.

Este artigo tem como objetivo levantar elementos que possibilitem a discussão acerca da informação e das relações de poder no âmbito organizacional contemporâneo ${ }^{1}$.

1 Considera-se aqui contemporâneo o conjunto dos fenômenos da época atual, recente, que acontece agora no plano cultural e social. Moderno, pós-moderno e contemporâneo se aproximam em certos aspectos e não se dão linearmente na história. Como M. Maffesoli (No fundo das aparências. Petrópolis: Vozes, 1999. p. 14), entende-se que "sem entrar num debate estéril sobre a própria noção, a pós-modernidade seria essa mistura orgânica de elementos arcaicos e de outros um pouco mais contemporâneos". Entende-se por Modernidade o período histórico marcado pela cisão entre as esferas do conhecimento, entre religião e ciência, marcadamente após o século XVI e o pensamento de Descartes, passando pelo Século das Luzes, a Revolução Industrial e suas conseqüências sociais, culturais e econômicas. Como escreveu Stuart Hall, "as transformações associadas à modernidade libertaram o indivíduo de seus apoios estáveis nas tradições e nas estruturas" (A identidade cultural na pós-modernidade. 3.ed. Rio de Janeiro: DP\&A, 1999. p. 25). E tomase pós-modernidade como o faz Fredric Jameson (O pós-modernismo e a sociedade de consumo. In: KAPLAN, A. O mal-estar no pós-modernismo: teorias e práticas. Rio de Janeiro: Jorge Zahar, 
Os conceitos de informação e poder são empregados explícita ou implicitamente em todas as atividades de Relações Públicas. Assim, rever reflexivamente noções para compreender melhor esse contexto justifica-se em um campo profissional e para um objeto de estudo de características interdisciplinares.

Em termos metodológicos, trata-se de uma pesquisa qualitativa fundamentada em referencial bibliográfico com intuito de construir uma reflexão acerca da temática estudada. Como pesquisa qualitativa, "preocupa-se com um nível de realidade que não pode ser quantificado” (MINAYO, 1998, p. 20). Conceitualmente, partiu-se da questão do "excesso de informação" promovido a partir do século XX, desde o advento da cultura de massa até as redes de computadores. Em seguida, buscou-se realizar uma problematização acerca de poder e sua dialética no âmbito das organizações, pensados especialmente com base na abordagem de J. Kenneth Galbraith, na obra Anatomia do poder (1986). Tal relação se constrói também - mas não apenas - com base na circulação de informação. O texto se encerra com uma discussão acerca das relações de comunicação e de poder e das Relações Públicas partindo do pensar de autores como Parés I Maicas (2004), Kunsch (2004 e 1997) e Peruzzo (1982).

\section{Informação e excesso: das indústrias culturais às memórias digitais}

Mudanças sociais, culturais e econômicas no final do século XIX e início do século XX associadas ao incremento tecnológico propiciaram o advento do fenômeno chamado pejorativamente por Adorno e Horkheimer (1982) de Indústria Cultural. Na visão dos autores, a reprodução em larga escala promovida por essa "indústria" conferiria a tudo "um ar de semelhança", criando "produtos culturais" não-originais, "um modelo do gigantesco mecanismo econômico" (1982, p. 165).

Em uma avaliação distinta, autores funcionalistas americanos ou "integrados", como os alcunhou Umberto Eco (1970), denominaram o fenômeno de "cultura de massa" e entenderam que, na realidade, colocavam-se "os bens culturais à disposição de todos, tornando leve e agradável a absorção das noções e a recepção de informações" (ECO, 1970, p. 9).

Embora divergentes, essas abordagens e outras mais recentes - que levam em consideração as possibilidades críticas da esfera da recepção e que a cultura funciona como um filtro das mensagens veiculadas pelos meios de comunicação de massa - le-

1993). Segundo o autor, há contemporaneamente um "sentimento geral de que, em algum momento posterior à segunda guerra, um novo tipo de sociedade começou a emergir" (1993, p. 43). Entre suas características, a Pós-modernidade teria o esmaecimento de fronteiras e separações fundamentais, em especial entre "alta" cultura e cultura de massa e entre as diferentes áreas teóricas. Outros aspectos seriam a fragmentação e a presença significativa do pastiche, a cópia sem referência. 


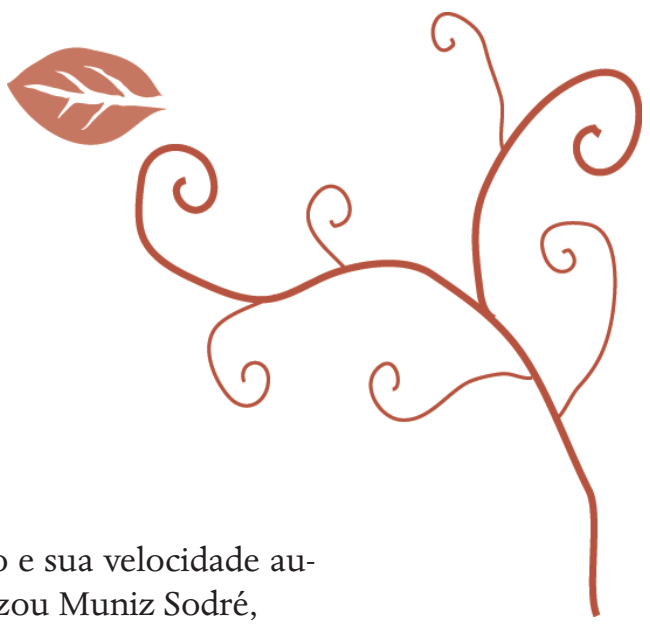

mentaram de forma exponencial no século XX. E como sintetizou Muniz Sodré,

"as necessidades do processo acumulativo ou de reprodução ampliada do capital central exigem também uma maior velocidade de circulação de dados e saberes no interior dos aparatos produtivos, tanto no nível das máquinas de construção (fábricas, usinas) como nos processos de gestão". (1987, p. 51)

A produção de informação se multiplicou e alcançou diversas etapas do processo econômico, mas também se espraiou para outros setores da sociedade: saúde, educação, consumo. Assim, nas sociedades em que a cultura de massa e o consumo conspícuo de bens materiais e simbólicos se expandem, a informação torna-se elemento essencial para a coesão e a organização social. Observa-se, então, que discursos midiáticos - da imprensa, da publicidade, das narrativas ficcionais televisionadas -, assim como discursos políticos, consistem em tentativas de se obter apoio a algum exercício - implícito ou explícito - de poder.

Enquanto os meios de comunicação de massa, as grandes agências internacionais de notícias e as de publicidade, os diversos tipos de assessorias de comunicação e imprensa trabalham gerando informações, criando padrões, o excesso parece banalizar o valor esclarecedor que a informação poderia ter.

Do ponto de vista de quem recebe as informações - e é difícil, nas sociedades contemporâneas, não ser exposto a elas - parece que uma das estratégias para lidar cognitivamente com o excesso seja ignorá-lo. Outra estratégia seria efetivar seu consumo: ter acesso à informação e depois apagá-la ou esquecê-la. Uma terceira seria gerar um processo dialético de "resistência" que incrementaria cada vez mais os movimentos alternativos de comunicação comunitária estimulados especialmente por organizações não-governamentais - o chamado terceiro setor.

É nesse contexto de excesso de informação irrelevante que a Comunicação Organizacional busca ser uma maneira de permitir a participação das instituições na vida social, 
INFORMAÇÃO, RELAÇÕES DE PODER E COMUNICAÇÃO NAS ORGANIZAÇÕES: UMA REFLEXÃO SOBRE O CAMPO • DENISE DA COSTA OLIVEIRA SIQUEIRA

fora do âmbito estritamente econômico. Pensar sobre Comunicação Organizacional, então, leva a refletir sobre o excesso de informação produzido por inúmeras fontes e com o qual a informação institucional concorre.

Essa produção e utilização intensiva da informação na contemporaneidade gerou termos como revolução informacional. Jean Lojkine esclarece que tal fenômeno extrapola o nível da produção de dados por meio do uso intensivo de computadores. Segundo o autor,

"a revolução informacional não se reduz a potencialidades sociais da micro-eletrônica; antes, manifesta-se no conjunto de formas novas da informação que ela mobiliza, notadamente nos circuitos da inovação na empresa e nas redes que vinculam indústrias, serviços e pesquisa científica". (1995, p. 38)

Dessa forma, a "revolução" a que o autor se refere parece envolver não somente a produção hipertrofiada de informação, mas a sua valorização, reorganização e os seus modos de utilização nas organizações (1995, p. 252).

A revolução informacional alcança o universo das organizações e nelas o campo de sua comunicação, uma vez que nele informação é matéria-prima. O profissional que lida com essa área trabalha na apuração, seleção, filtragem, edição de informações. No entanto, sabe-se que permeia esse processo um conjunto de interesses relativos a um outro conjunto de relações de poder. Assim, o caráter público da informação nas organizações - e fora delas também - não significa um caráter democrático, socializado.

A questão do excesso de informação está, de certa forma, associada à industrialização, à urbanização, à concentração de população nas cidades e à tecnologia. As indústrias da informação e da cultura se estabeleceram a partir da concepção da informação como bem econômico no século XX. Em termos conceituais, sua origem está relacionada à separação das ordens do conhecimento e ao que Max Weber chamou de racionalização ou de desencantamento do mundo. Ao conceituar racionalização, Weber (1994) escreveu que uma ação social racional a fins significa cumprir determinadas etapas racionais para atingir certo resultado por meios e instrumentos racionais.

Weber classifica a ação social de quatro modos distintos ${ }^{2}$, mas complementares, que visam a possibilitar a análise sociológica. Nenhum desses tipos pode ser encontrado em seu estado puro na realidade empírica, mas todos servem como parâmetros capazes de mostrar em que medida a realidade se afasta ou se aproxima deles. $\mathrm{O}$ autor afir-

2 A saber: modo racional referente a fins (expectativa quanto ao comportamento); modo racional referente a valores (crença no valor); modo afetivo (estado emocional); modo tradicional (costume arraigado) (WEBER, 1994, p. 16). 
ma que "só muito raramente a ação, e particularmente a ação social, orienta-se exclusivamente de uma ou de outra destas maneiras” (WEBER, 1994, p.16). Ainda segundo Weber, a relação social - dada com base na ação social - consiste "completa e exclusivamente na probabilidade de que se aja socialmente numa forma indicável" (1994, p. 16), ou seja, espera-se que em determinada situação as pessoas ajam de determinado modo.

Entendida e explorada como bem econômico, informação se tornou objeto de ações racionais visando a alcançar determinados fins - a saber: construir e manter relações de poder econômico, político e social. No âmbito das organizações, visa a estabelecer comunicação com públicos internos e externos, a manter e/ ou ampliar "mercados", a promover atualização da "cultura" organizacional, enfim, a normatizar, disciplinar, em prol da permanência/ preservação da instituição. Assim, visa a estimular determinadas "ações sociais", como Weber as conceituou. Entre essas ações sociais, destaca-se a construção de uma identidade social da organização, ou seja, como ela quer ser vista.

Isso não significa, no entanto, que todos dentro da organização receberão e acatarão as informações da forma como os responsáveis pela circulação/envio daquela informação previram. Afinal, o "sistema" é composto de pessoas, sujeitos, com seus valores e visões de mundo diferenciados. É preciso considerar, parafraseando a antropóloga Livia Barbosa (2002), que a esfera simbólica - os valores, as crenças, os símbolos - tem importância no comportamento das pessoas em sua vida pessoal assim como na profissional, portanto, reflete-se nas organizações, em seu desempenho, em sua comunicação. É uma questão de ordem cultural que perpassa as organizações e não pode ser ignorada.

Se a indústria cultural associada ao desenvolvimento tecnológico tornou acessível uma quantidade inimaginável de informação ao longo do século passado, na década final do século XX, as tecnologias surgidas a partir da implementação das redes de computadores e sua consolidação como meio de comunicação fizeram pensar especialmente sobre a memória e a transmissão de saber e de informação. Uma rede de computadores é, na realidade, um conjunto de memórias digitais ligadas entre si. As informações contidas em arquivos gravados em máquinas espalhadas por vários países podem ser consultadas com velocidade e comodidade pelos grupos sociais que têm acesso a essa tecnologia. E como escreveu Gilberto Prado,

"O funcionamento atual das redes nos faz vislumbrar um novo paradigma com a possibilidade tecnológica de difusão de "Muitos" para "Muitos", no qual um indivíduo com acesso a recursos minimos pode funcionar como um produtor significativo de informação, de forma isolada ou criando redes, comunidades, grupos, que potencialmente podem 'concorrer' ou relativizar ofluxo de informação unidirecionado e prevalente das midias tradicionais." (2005, p. 45) 
A explosão da informação exige máquinas cada vez mais potentes, com maior capacidade de memória. Memória, no universo dos computadores, será, então, sinônimo de capacidade de armazenamento de dados em linguagem digital. Ao público ou aos usuários "comuns", essa expansão chega sob a forma de mais espaço na memória de computadores, de provedores de acesso à Internet, de e-mails e suportes que sempre suplantam os modelos anteriores (disquetes, CD-ROM, DVD, pen drive).

No campo social - e também no da subjetividade - memória é construção e reconstrução. Memória não tem o sentido apenas de retenção ou lembrança, mas de conteúdo e de suas relações com interesses sociais e culturais. Os conteúdos adquiridos na experiência podem ser alterados quando lembrados. As recordações tendem, portanto, a concentrar-se nos interesses de quem se lembra.

Se as informações que chegam abundantemente a ouvintes, leitores, espectadores não lhes interessam diretamente, logo podem ser esquecidas. Por isso, é comum folhear revistas com muitas fotos e pouco texto e depois não se lembrar do que foi "visto/lido". No mesmo sentido, pode-se assistir a um telejornal e não se lembrar logo depois o que foi noticiado ou, ainda, apagar e-mails antes mesmo de lê-los por inteiro, imediatamente esquecendo-se do pouco que foi lido. E quando a informação é de interesse, pode ser logo modificada: informação, como apontou Lévy (1997), é virtual. Assim, "quando utilizo a informação, ou seja, quando a interpreto, ligo-a a outras informações para fazer sentido, ou quando me sirvo dela para tomar uma decisão, atualizo-a” (LÉVY, 1997, p.58).

As máquinas, aliás, são ótimas como metáfora para a memória na era da informação: apagam-se informações antigas para dar lugar às novas. Essa é a lógica do consumo que parece reger também o universo da informação em excesso, fazendo o esquecimento, paradoxalmente, ter tanta importância quanto a memória.

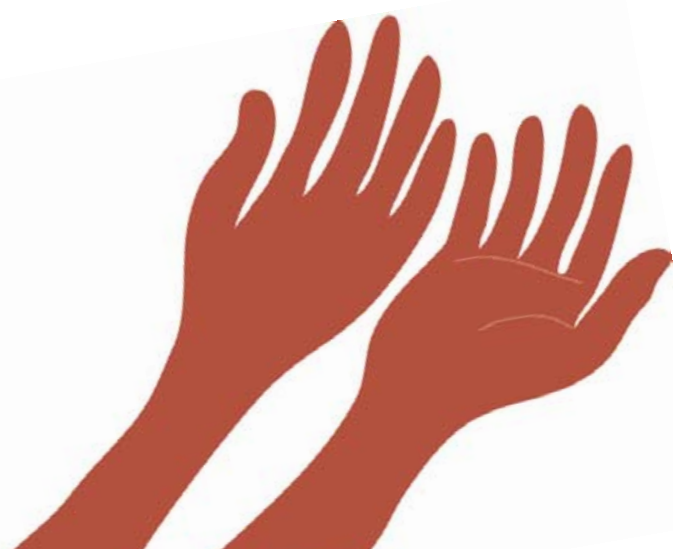


INFORMAÇÃO, RELAÇÕES DE PODER E COMUNICAÇÃO NAS ORGANIZAÇÕES: UMA REFLEXÃO SOBRE O CAMPO - DENISE DA COSTA OLIVEIRA SIQUEIRA

\section{Poder, dialética e as organizações}

Convencer, criar polêmicas, simular discussões são características dos mass media, dos políticos, dos diversos tipos de organizações que querem obter adesão. A noção - eticamente equivocada - de que verdadeiro é o que é aceito pela audiência, se encaixa bem no que parece ser o tipo de entendimento que os meios de comunicação valorizam. Neles, "celebridades" buscam fama - mesmo que efêmera -, mostram-se, explicam ações privadas publicamente, buscam despertar interesse de um público que consome revistas de fofocas, programas de televisão e rádio, sites na Internet.

Persuasão, retórica e ideologia estão estreitamente relacionadas com as relações de poder. No universo contemporâneo, no modo de vida urbano e industrializado, multiplicam-se campanhas publicitárias, textos jornalísticos, campanhas institucionais, propaganda eleitoral e toda uma gama de jogos de interesses que tendem a manter o status quo - ou "as coisas como estão". Nesse sentido, a comunicação de massa, a Comunicação Institucional e mesmo a "grande imprensa" não buscam transgredir ou revolucionar. São muitos os comprometimentos no momento de veicular informações para "ousar" ou tomar posicionamentos de vanguarda. Transgressão, vanguarda, "revolução" parecem termos restritos - contemporaneamente - ao campo das artes e, mesmo esse, também envolve interesses.

No entanto, recursos persuasivos e retóricos podem ser utilizados para combater poderes institucionalizados. O poder é um valor dialético que, quando exercido, gera outras fontes de poder contraditórias a sua volta: a apresentação e defesa de um ponto de vista podem fazer surgir idéias opostas (GALBRAITH, 1986). Assim ocorre com os meios de comunicação de massa e sua tendência ao conformismo, aos quais a resistência cultural faz oposição, ou ao fenômeno da globalização que, apresentando tendências globais dialeticamente, faz ganhar força características culturais regionais.

Valores, costumes, mitos, rituais, éticas e relações de poder são elementos das culturas que agem no sentido de viabilizar a vida social, criando relações sociais institucionalizadas que possibilitem aos indivíduos viver em grupo. Essas regras - e os modos como são aceitas, rejeitadas ou transgredidas - variam de cultura para cultura. As organizações - lucrativas ou não - também refletem as contradições geradas pelo acúmulo de poder. A elas se opõem outros grupos com outros interesses.

Uma organização é um sistema no qual se apresenta uma preocupação com a racionalidade, os processos logísticos, as hierarquias. Um sistema organizacional "se viabiliza graças ao sistema de comunicação nele existente, que permitirá sua realimentação e sua sobrevivência" (KUNSCH, 1986, p. 29). Assim,

"As organizações constituem um sistema cujos elementos são interdependentes, formando um todo unitário. A dinâmica organizacional, que visa a coordenar recursos 
humanos e materiais para atingir objetivos definidos, se processa por meio da interligação e do relacionamento dos membros. Estes, por sua vez, são informados e informam ininterruptamente, fornecendo a um centro comum o andamento da organização". (KUNSCH, 1986, p. 29)

Nas organizações, a informação circula internamente, entre os diferentes níveis que as compõem, mas também externamente, entre diferentes organizações. Em organizações privadas, do tipo empresa, em que informação é vista como capital, os dados tendem a circular mais rapidamente. Em organizações não-lucrativas, como o Estado e suas instituições, em que tudo precisa ser conferido e comprovado, a circulação tende a ser mais morosa. Em ambos os tipos, informação é poder e pode ser negociada, partilhada ou negada.

O poder pode ser considerado a faculdade de exercer influência física ou moral sobre o(s) outro(s); no plano simbólico, a capacidade de se definir a realidade para os outros. Os homens e suas instituições buscam poder por intermédio da negociação política, do uso da violência, do emprego de idéias religiosas. De acordo com Kaplan e Lasswell, "o poder pode repousar sobre credos e lealdades tanto quanto sobre interesses, sem falar do hábito e da apatia. E mesmo quando prevalece o elemento da coação, não é necessário que tenha forma de violência” (1979, p.112).

Inseridas em um universo social e cultural, as relações de poder refletem valorações, hierarquias, modos de sanção relativos à cultura em que são exercidas. Assim, "a relação de poder pressupõe valorizações específicas: falamos de poder como um controle sobre práticas e padrões de valor. Ademais, as sanções, que não têm eficácia se sua aplicação não constituir de fato uma privação, pressupõem valores" (KAPLAN, LASSWELL, 1979, p. 112).

Há nas sociedades contemporâneas, assim como houve nas anteriores, grupos que exercem poder e grupos que se submetem ou se opõem ao poder. Geralmente, os grupos que exercem poder buscam legitimidade. No entanto, governos, empresas ou sindicatos podem ser poderosos, mas podem, também, ter seu poder dissolvido ou fracionado por grupos opostos por meio de estratégias políticas e econômicas que se valham do uso da força ou de negociação. A título de exemplificação, pode-se levar a crer que o exercício de determinado poder é impróprio, ilegítimo, inconstitucional ou opressivo e que tal poder deveria ser contido ou coibido pela sociedade (GALBRAITH, 1986, p. 78). Na realidade, tal poder realmente pode ser inaceitável ou constituir um outro modo de concentração de energias, destoante ou contrário à ordem já estabelecida e aceita pela maioria.

Os meios de comunicação de massa - a "grande mídia" - constroem discursos, defendem pontos de vista em relação aos mais diversos assuntos. Às vezes, parecem legítimos, outras vezes, não explicitam interesses por trás das falas veiculadas. Esse foi o 
caso da cobertura jornalística sobre o tráfico de drogas no Rio de Janeiro, no segundo semestre de 2002. Após o assassinato do jornalista Tim Lopes, que fazia uma série de reportagens para a Rede Globo sobre bailes funk financiados por traficantes, a mídia apelidou os traficantes de "quarto poder" em uma campanha que não era apenas contra os criminosos, mas também de teor político, revelando - para além do problema das drogas e das questões de saúde, sociais, policiais envolvidas - relações de poder, hierarquizações, valorações, disputas partidárias e por cargos políticos. ${ }^{3}$

Questões como o uso/ adoção de produtos geneticamente modificados, os transgênicos, na agricultura e na alimentação; a utilização de embriões humanos em pesquisas científicas; o desarmamento / proibição de comercialização de armas geram discussões sérias que circulam por diversos setores da sociedade, inclusive, a mídia, reforçando discursos e deixando entrever que há diversos interesses permeando as falas ou vozes.

Em relação a essas questões, cada grupo social envolvido tenta persuadir os outros para que acatem e apóiem seus interesses. E todos buscam a adesão da comunidade em geral. Nesses casos, as discussões explicitam os três tipos de poder classificados por Galbraith (1986): o poder condicionado (exercido mediante mudança de crença ou de convicção devido à persuasão, à educação ou ao compromisso social); o poder condigno (obtenção de submissão pela capacidade de impor às preferências do indivíduo ou do grupo uma alternativa suficientemente desagradável ou dolorosa para levá-lo a abandonar essas suas preferências) e o poder compensatório (conquista da submissão por meio da oferta de uma recompensa positiva - proporcionando algo de valor ao indivíduo que assim se submete).

Conforme Galbraith, "a reação mais usual e eficaz a um exercício indesejável de poder é criar uma posição contrária de poder” (1986, p. 78). Esse raciocínio é chamado de dialética do poder - apresenta-se uma tese à qual se opõe uma antítese, com o objetivo de gerar uma síntese que satisfaça, em parte, ao grupo que defendeu uma causa e ao que se opôs a ela.

O pensamento dialético constrói-se com base nas contradições entre as partes (as diferenças entre elas) e da união dessas partes, em um esforço de síntese e análise da realidade. Trata-se, portanto, de avaliar a sociedade como um todo, ao mesmo tempo que como grupos sociais diferentes que se inter-relacionam. A dialética proporciona, então, a visão dos processos e inter-relações que compõem a realidade. Segundo

3 2002: a governadora do Rio de Janeiro por nove meses, Benedita da Silva, do Partido dos TrabaIhadores (PT), concorreu às eleições ao governo do Estado contra Rosângela Matheus, esposa do ex-governador Anthony Matheus, do qual Benedita da Silva fora vice-governadora. Anthony "Garotinho" se licenciou para concorrer à presidência da República contra Lula (PT) e Benedita da Silva assumiu o governo do Estado. Rosângela Matheus ganhou as eleições do Estado do Rio de Janeiro. Benedita da Silva se tornou ministra de Estado do governo Lula. 
INFORMAÇÃO, RELAÇÕES DE PODER E COMUNICAÇÃO NAS ORGANIZAÇÕES: UMA REFLEXÃO SOBRE O CAMPO - DENISE DA COSTA OLIVEIRA SIQUEIRA

Konder, o "método dialético nos incita a rever o passado à luz do que está acontecendo no presente; ele questiona o presente em nome do futuro, o que está sendo em nome do que 'ainda não é’” (1983, p. 84).

A dialética propõe, então, um movimento constante e não uma solução. A relação entre ela e a noção de poder é forte. O poder também se movimenta constantemente e mesmo para mantê-lo, é preciso reconstruí-lo sempre.

\section{Relações de comunicação, de poder e públicas: considerações finais}

Com base nas grandes produções proporcionadas pelas máquinas da Revolução Industrial - reforçadas e atualizadas hoje pelas novas tecnologias digitais - consolidouse a presença de um grande "público consumidor". Tal "público" incumbiu-se do consumo de bens de ordem material e também dos chamados "produtos culturais", acessíveis a várias classes, com características que visam a satisfazer a uma espécie de "média" da população.

É nesse contexto, no início do século XX, que se consolidam a cultura de massa e os meios de comunicação de massa. É a era do desenvolvimento de uma linguagem, um código padronizado, repetido como fórmula que visa a se fazer entender por uma audiência ampla e heterogênea. A comunicação de massa assume papel preponderante nessa nova ordem, veiculando imagens plenas de valores, conceitos e preconceitos.

A indústria cultural busca lucro, precisa de anunciantes e parceiros econômicos para manter-se e de audiência para manter os anunciantes. Seus discursos e das organizações que nela anunciam são comprometidos política e economicamente, o que implica, eventualmente, construir discursos sobre "responsabilidade social", cidadania e assuntos considerados como prestação de serviços para a comunidade. Estabelece-se um novo tipo de relação de comunicação, mediada por canais impessoais, destinada a um "público" anônimo. Comunicação em uma só via: dos meios para o receptor.

Nesse contexto de comunicação impessoal, anônima, dirigida a multidões, também surgem técnicas que visam a promover comunicação entre grupos específicos ou "públicos". Entendidas como agente dialético, as Relações Públicas utilizam elementos persuasivos, argumentos, para defender determinados posicionamentos. Podem, portanto, gerar alienação ou estimular análise crítica. Para isso, é fundamental contextualizar (com pesquisa e planejamento) as ações de Relações Públicas e entendê-las como parte das relações sociais, das relações de comunicação e de poder. Assim, mantém-se atual a assertiva de que

"ao estudar as Relações Públicas em si mesmas, ao isolá-las do conjunto das Ciências Sociais dentro da dinâmica capitalista, e ao não apanhar suas imbricações na dialéti- 
ca social, está se seccionando a realidade de tal sorte a perder a visão de conjunto. Perdendo a visão de conjunto, deixa-se de ver a realidade e existe a perda da visão da trama das relações sociais". (PERUZZO, 1982, p. 133)

Entender as Relações Públicas como parte das relações sociais implica impor a elas conceitos como ética. A proximidade com usos de retórica, persuasão, relações de poder fazem das atividades ligadas às Relações Públicas e à Comunicação Organizacional um campo em que a ética profissional deve estar sempre em discussão. A desconsideração da ética, do senso crítico e da responsabilidade de quem busca convencer os outros a favor de suas causas acaba levando à falta de credibilidade ou como apontou Parés I Maicas, ao "riesgo que la información se convierta en propaganda o en desinformación” (2004, p. 85).

Essa postura é fundamental, uma vez que pensar em informação envolve contextualizá-la, apontar de que ponto de vista está sendo tomada, como e por quem foi produzida, com que objetivo está sendo divulgada. Refletir sobre informação na era do "excesso de informação" implica, então, "desconfiar" de toda mensagem que se recebe e agir criticamente em relação a ela. Torna-se necessário entendê-la como fruto de uma relação social: informação produzida tende a circular, implica relação entre agentes que enunciam e interagem. É importante quem produz essa informação estar ciente disso porque quem a recebe pode estar.

Assim entendendo, as Relações Públicas podem agir a favor (ou contra) as organizações, conscientizando (ou alienando) por meio da informação e utilizando como instrumento uma argumentação coerente com o público que precisa das informações transmitidas. Esse é um foco distinto do que prevaleceu durante boa parte da história das Relações Públicas e da Comunicação Organizacional: transmitir o que possa ser do interesse da sociedade e não pensar somente do ponto de vista da instituição. Comunicação objetiva, como demanda a velocidade da época, honesta, fidedigna, de interesse, contextualizada, indicando fontes para mais informações do leitor, espectador, ouvinte ou internauta que desejar.

O contrário disso é adotar o procedimento que rege os spams, aqueles e-mails que se recebe sem tê-los solicitado, que, em geral, não são do interesse do usuário da Internet, fazem-no perder tempo e acabam sendo apagados antes de ser lidos. Spams e pop-ups - caixas de publicidade que se recebe ao ter acesso a determinados sites da Web - são atualizações em versão tecnológica do exercício retórico, persuasivo e da "superinformação inútil”. Nessa linha, Comunicação Organizacional somente terá sentido e utilidade quando acontecer tendo como foco os interesses de quem recebe as mensagens. Somente assim despertará sua atenção em um universo de novas tecnologias no qual as relações de poder parecem se diluir, mas ocupam paulatinamente novos espaços. De outra forma, será apenas mais informação, confundindo-se com o excesso já em circulação ou, até mesmo, provocando antipatias, enfim, resistências. 
INFORMAÇÃO, RELAÇÕES DE PODER E COMUNICAÇÃO NAS ORGANIZAÇÕES: UMA REFLEXÃO

SOBRE O CAMPO • DENISE DA COSTA OLIVEIRA SIQUEIRA

\section{Bibliografia}

BARBOSA, Livia. Cultura e empresas. Rio de Janeiro: Jorge Zahar, 2002.

BAUDRILLARD, Jean. As estratégias fatais. Rio de Janeiro: Rocco, 1996.

BRIGGS, Asa; BURKE, Peter. Uma história social da mídia: de Gutenberg à Internet. Rio de Janeiro: Jorge Zahar, 2004.

ECO, Umberto. Apocalípticos e integrados. São Paulo: Perspectiva, 1970.

GALBRAITH, John Kenneth. Anatomia do poder. 2.ed. São Paulo: Pioneira, 1986.

KAPLAN, Abraham; LASSWELL, Harold. Poder e sociedade. Brasília: Ed. Universidade de Brasília, 1979.

KONDER, Leandro. O que é dialética. 6.ed. São Paulo: Brasiliense, 1983.

KUNSCH, Margarida M. K. Organizações, cidadania, comunicação e os limites entre as estratégias e a ética. In: BRAGANC̦A, Aníbal; MOREIRA, S. (orgs.). Mídia, ética e sociedade. Belo Horizonte: PUC-MG-Intercom, 2004. p. 95-114.

. Relações públicas e modernidade: novos paradigmas na comunicação organizacional. São Paulo: Summus, 1997.

. Planejamento de relações públicas na comunicação integrada. 3.ed. São Paulo: Summus, 1986.

LÉVY, Pierre. O que é o virtual. São Paulo: 34, 1997.

LIMA, Luiz Costa. Comunicação e cultura de massa. In: (org). Teoria da cultura de massa. 3.ed. Rio de Janeiro: Paz e Terra, 1982. p. 13-68.

LOJKINE, Jean. A revolução informacional. São Paulo: Cortez, 1995.

MINAYO, Maria Cecília de S. Ciência, técnica e arte: o desafio da pesquisa social. In: cial: teoria, método e criatividade. 10.ed. Petrópolis: Vozes, 1998. p. 9-30. (org.). Pesquisa so-

PARÉS I MAICAS, Manuel. Etica de la comunicación institucional. In: BRAGANC̣A, Aníbal; MOREIRA, S. (orgs.). Mídia, ética e sociedade. Belo Horizonte: PUC-MG-Intercom, 2004. p. 79-88.

PERUZZO, Cicilia Krohling. Em busca dos objetos de pesquisa em comunicação no Brasil. In: WEBER, Maria Helena; BENTZ, lone; HOHLFELDT, Antonio (orgs.). Tensões e objetos da pesquisa em comunicação. Porto Alegre: Sulina, 2002. p. 52-72.

Relações públicas no modo de produção capitalista. São Paulo: Summus, 1982.

PRADO, Gilbertto. Redes e espaços artísticos de intervenção. In: BENTES, Ivana (org.). Corpos virtuais. Rio de Janeiro: Centro Cultural Telemar, 2005. p. 45-49.

SIQUEIRA, Denise da C. O.. Persuasão, poder e dialética em relações públicas. In: FREITAS, R.; LUCAS, Luciane (orgs.). Desafios contemporâneos em comunicação: perspectivas de relações públicas. São Paulo: Summus, 2002. p. 111-137. 
INFORMAÇÃO, RELAÇÕES DE PODER E COMUNICAÇÃO NAS ORGANIZAÇÕES: UMA REFLEXÃO

SOBRE $O$ CAMPO - DENISE DA COSTA OLIVEIRA SIQUEIRA

SODRÉ, Muniz. Sociedade e informática. In: CARNEIRO LEÃO, E. (org.). A máquina e seu avesso. Rio de Janeiro: Francisco Alves, 1987. p. 45-60.

WEBER, Max. Conceitos sociológicos fundamentais (cap. I). In: . Economia e sociedade: fundamentos da sociologia compreensiva (v.1). 3.ed. Brasília: Ed. UNB, 1994. p. 3-35.

WOODWARD, Kathleen (org.). The myths of information: tecnlology and postindustrial culture. Londres: Routledge \& Kegan Paul, 1980.

ANO $3 \cdot$ NÚMERO $5 \cdot 2^{\circ}$ SEMESTRE DE $2006 \cdot$ organicom • 27 